\title{
Ability of Gamma-Irradiated Polyvalent Antivenin to Neutralize the Toxicity of the Egyptian Cobra (Naja haje) Venom
}

\author{
Esmat A. Shaban* and Manar N. Hafez** \\ *Drug Rad. Res. Dept. and **Rad. Biol. Res. Dept. \\ National Center for Radiation Research and Technology, \\ Atomic Energy Authority, Cairo.
}

\begin{abstract}
In this study, the lethality as well as the biochemical and histological effects of Cobra (Naja haje) envenomation at a sublethal dose has been investigated in mice and rats.

The venom injected intraperitoneally in rats $(0.2 \mathrm{mg} / \mathrm{kg})$ produced marked increase in the activities of ALT, AST, ALP and LDH. Also, serum glucose, urea and creatinine levels were significantly elevated. These results are in accordance with the histological findings of the liver that showed vacuolated hepatocytes and scattered necrotic and haemorrhagic areas together with congestion and dilatation of blood vessels and sinusoids. The spleen also displayed small diffuse white pulps with ill-defined outlines and extravasation of blood that extended to infiltrate the widened sinusoids. The venom also produced severe degeneration of the cardiac muscle with loss of striations and extensive haemorrhage inbetween the myocardial bundles.

These biochemical and histological envenomation disorders, were markedly and effectively neutralized by the polyantivenins (non-irradiated and gamma-irradiated in a sterilizing dose of $25 \mathrm{kGy}$ ). The neutralization ability of both antivenins was the same against a lethal dose of the venom $\left(2.5 \mathrm{LD}_{50}\right)$. The minimal protective dose of the polyantivenins was calculated to be $16000 \mu \mathrm{g} / 20 \mathrm{gm}$ mouse. Rats injected with mixtures of venom and antivenins (non-irradiated and irradiated) showed a decrease in all elevated biochemical parameters investigated. The histological examination also showed less severe injuries in all organs examined (liver, spleen and heart) which appeared more or less normal with very few abnormalities remaining.

Comparative study was also done on these antivenins using immunodiffusion technique which showed the same precipitin bands with the tested venom. Thus, it can be concluded that both antivenins (non irradiated and 25 KGy gamma-irradiated) have similar immunoglobulins and have no differences in their antilethal and enzymatic neutralizing ability as well as in ameliorating the degree of tissue damage induced by the venom.
\end{abstract}

\section{INTRODUCTION}

Poisoning by snake bite is a real clinical problem, espesially in tropical areas, and efficacious treatment should, therefore, be available. Since the beginning of this century, antivenom serotherapy constitutes the major therapeutic approach (Chippaux, 1991).

In Egypt, there are many varieties of snakes, some of them cause severe damage to snake bite victims like Egyptian Cobra,
Cerastes cerastes, etc.... A polyvalent antivenin prepared against Naja haje, Cerastes cerastes, Cerastes viper and Naje nigrocolus is widely used in Egypt in the treatment of envenomation. Usually, vaccines and sera are prepared under aseptic conditions and filtered through bacterial filters. This procedure involves an extensive and strict aseptic conditions which makes the product very expensive. 
Furthermore, there is a high risk of contamination during packing that may lower their quality.

Irradiation provides an alternative technique for sterilizing vaccines and sera when it is already prepared and packaged. This process, in addition of being convenient, precludes any bacterial or viral contamination of the product during production or packing (Tumanyan, 1973). The radiation sterilization of prepared vaccines and sera involves an exposure to high doses of radiation (up to $25 \mathrm{kGy}$ ), which kills even highly radioresistant bacteria including the spore forming types (Poctor and Goldblith, 1953). In a previous study, an attempt has been made by Shaban (1990) to investigate the effect of gammairradiation on scorpion Androctonus amoreuxi antivenin (in its aqueous form). It has been found that the low radiation level of $15 \mathrm{kGy}$ did not alter the neutralizing capacity of the antivenin. However, the neutralizing capacity decreased after 30 kGy gamma-irradiation.

There is a growing body of experimental evidence in support of the concept that neutralization of the lethal effect does not necessarily correlate with neutralization of other toxic activities, since specific pharmacologic properties of venoms depend on different toxins. The World Health Organization (WHO) has recommended the evaluation and standardization of antivenoms based on the neutralization of specific pharmacologic effects (WHO, 1981). Therefore, it is essential to examine the relative qualities of different commercial antivenoms with respect to various activities of snake venoms (Gutierrez et al. 1988; Rogas et al. 1990 and Harvey, 2000). For instance, it has been demonstrated that although the polyvalent antivenin used in Costa Rica is very effective in neutralizing the lethal effect of snake venoms (Bolanas and Cerdas 1980), it neutralizes oedemaforming and myotoxic activities of some venoms less efficiently (Lomonte, 1985).

Upon the previous findings, it was of interest to test the venom-neutralizing capacities of non-irradiated and irradiated antivenin. In this study, the results of the utilization of both non-irradiated and gamma-irradiated antivenin against Egyptian Cobra (Naja haje) venom are presented. Their ability to neutralize lethal and toxic tissue damaging activities as well as their ability to ameliorate the deleterious histopathological responses induced by envenomation on some vital organs of rats (liver, spleen and heart) is examined.

\section{MATERIALS AND METHODS Venom:}

Pooled venom of Naja haje was provided by the serpentarium, poison center, Faculty of Medicine, Ain Shams University. Pooled venom of Naja haje extracted from healthy snakes was dried, lyophilized and kept in refrigerated dessicator.

\section{Antivenin:}

Egyptian polyantivenin prepared against Naja haje, Cerastes cerastes, Cerastes viper and Naja nigrocolus was obtained as a gift from the Egyptian Organization of Biological Products and Vaccines, Agouza, Cairo, Egypt. The lyophilized polyvalent antivenin was dissolved in $10 \mathrm{ml}$ distilled water before use.

\section{Animals:}

Albino Swiss mice weighing between 20 - 22 gm, and albino rats weighing 120 150 gm were used in this study.

Animals were maintained under standard conditions of boarding and given standard food and water ad Libitum.

\section{Irradiation of antivenin:}

Gamma-irradiation of polyantivenin was carried out at the National Center for Radiation Research and Technology, Cairo, Egypt, using a cobalt-60 gamma cell 220 . The radiation dose rate was $1.41 \mathrm{rad}$ per second.

In this study samples of lyophilized antivenin were subjected to integral radiation dose level of $25 \mathrm{kGy}$. Non irradiated polyantivenin of the same batch was used as control. The lyophilized samples of polyantivenin were used in this study to avoid ionization of the water content into oxygenated water, which would modify and oxidize the protein. 


\section{Esmat A. Shaban \& Manar N. Hafez}

\section{Immunodiffusion technique:}

Immunodiffusion plates were prepared using 1.2 percent Nobelagar (Difco Lab., Detroit, Mich.) in 0.9 percent sodium chloride solution. Sodium azide in a concentration of 0.05 percent was added to retard bacterial growth. Double diffusion experiments were carried out as described by Ouchterlony (1948). The wells were filled with $20 \mu \mathrm{l}$ volumes and after developing of the precipitin bands (48 hr), the plates were washed for $24 \mathrm{hr}$ in $0.9 \%$ saline, dried and stained. The dried slides were stained with amidoschwartz 10B 0.5 percent in 5 percent acetic acid for $7 \mathrm{~min}$, washed with methanol acetic acid (9:1) dried in air and photographed.

\section{Lethality:}

Toxicity of venom was established before neutralization by the antivenin. Lethality was determined by i.p. injection of different doses of the venom to Swiss albino mice. The $\mathrm{LD}_{50}$ was calculated by the method of Spearman Karber (WHO, 1981), using six dosage levels. Six mice were used for each dosage.

Determination of venom-neutralizing capacities of non-irradiated and gammairradiated antivenin:

The venom neutralizing capacity of antivenins was obtained by determining the minimal amount of antivenin (nonirradiated and $25 \mathrm{kGy}$ irradiated) required to protect mice against a dose of $2.5 \mathrm{LD}_{50}$ $(12.5 \mu \mathrm{g})$ of venom per animal using the following procedure:

1- Different volumes of antivenins were mixed with a defined amount of venom and incubated at $37^{\circ} \mathrm{C}$ for $1 \mathrm{~h}$.

2-From each mixture a volume of $0.5 \mathrm{ml}$ (containing $2.5 \mathrm{LD}_{50}$ ) was injected (i.p) into groups of four mice.

3-The animals were observed for $24 \mathrm{hr}$ and death used as a criterion.

Antivenin irradiated by a dose of $25 \mathrm{kGy}$ was titrated against venom. The amount of irradiated antivenin needed to give the same degree of protection as in control antivenin was determined.
Mice of control group were injected with venom $(12.5 \mu \mathrm{g}$ in $0.5 \mathrm{ml})$ and treated with $0.5 \mathrm{ml}$ saline instead of the antivenin.

In all the experiments, the venom and the antivenin were thoroughly mixed in a test tube and incubated at $37^{\circ} \mathrm{C}$ for $1 \mathrm{hr}$. All injection volumes were maintained at 0.5 $\mathrm{ml}$ per mouse and made through i.p. injection. The number of dead mice in each group was recorded $24 \mathrm{hr}$ after injection. The group which had $100 \%$ survivors at the lowest quantity of antivenin injected was taken as the end point of the experiment. The quantity of irradiated antivenin in $\mu \mathrm{g}$ to neutralize the toxicity of $2.5 \mathrm{LD}_{50}$ of venom was calculated.

Each group consisted of at least four mice and all the experiments were repeated twice to determine the minimal protection dose of the antivenin.

\section{Effect of venom before and after neutralization by antivenins on enzymatic activity:}

Male albino rats (120-150gm) were divided into 6 equal groups, each group consisted of 6 animals.

Group 1: Control animals, received saline only $(0.1 \mathrm{ml})$.

Group 2: Injected with Naja haje venom $(0.2 \mathrm{mg} / \mathrm{Kg})$.

Group 3: Injected with non-irradiated antivenin (8 mg).

Group 4: Injected with 25 kGy gammairradiated antivenin ( $8 \mathrm{mg}$ ).

Group 5: Injected with a mixture of venom $(0.2 \mathrm{mg} / \mathrm{Kg})+$ non-irradiated polyantivenin (8mg), incubated at $37^{\circ} \mathrm{C}$ for $1 \mathrm{hr}$.

Group 6: Injected with a mixture of venom $(0.2 \mathrm{mg} / \mathrm{Kg})+25 \mathrm{kGy}$ irradiated polyantivenin (8mg) incubated at $37^{\circ} \mathrm{C}$ for $1 \mathrm{hr}$.

The animals were killed $24 \mathrm{hr}$ after injection. Serum was obtained by leaving blood samples to clot for half an hour in a refrigerator at $4^{\circ} \mathrm{C}$ then centrifuged for 20 min at 3000 r.p.m and the clear serum was separated carefully. Aspartate transaminase (AST) and alanine transaminase (ALT) were determined according to the method of Reitman and Frankel (1957). Lactate 
dehydrogenase was assessed using the method of Anon (1970), glucose was estimated according to Trinder (1969), the total and direct serum bilirubin in liver were calculated according to Doumas et al. (1973). Creatine kinase isoenzyme (CKMP) was determined using Boehringer Mannheim kits. Alkaline phosphatase was determined according to King and King (1956). Urea was estimated according to Patton and Crowtch (1977). Creatinine was determined according to Bowers and Wrong (1980).

Enzymatic activity was expressed as units per liter. The significance of the differences between the mean values of any two sets of observations was tested using Student's $t$-test (Bancroft, 1963).

\section{Histological Technique:}

The sacrificed rats in the previous experiments were quickly dissected and small pieces from liver, spleen and heart were rapidly removed and fixed in 10\% neutral buffered formalin for $24 \mathrm{~h}$. Following fixation, the specimens were carefully washed in running tap water, dehydrated in ascending series of alcohol, cleared in xylene and then embedded in paraffin wax. Sections of $5 \mu$ thickness were cut and stained with haematoxylin and eosin according to the method of Drury and Wallington (1980).

\section{RESULTS \\ Immunodiffusion test:}

The result of double immunodiffusion of non-irradiated and $25 \mathrm{kGy}$ gammairradiated polyantivenin against Cobra venom, showed similar patterns. The four visible lines obtained in the immunodiffusion reaction were identical and joined smoothly at the corners indicating that there was no change in antigenic determinants as shown in Fig. (1).

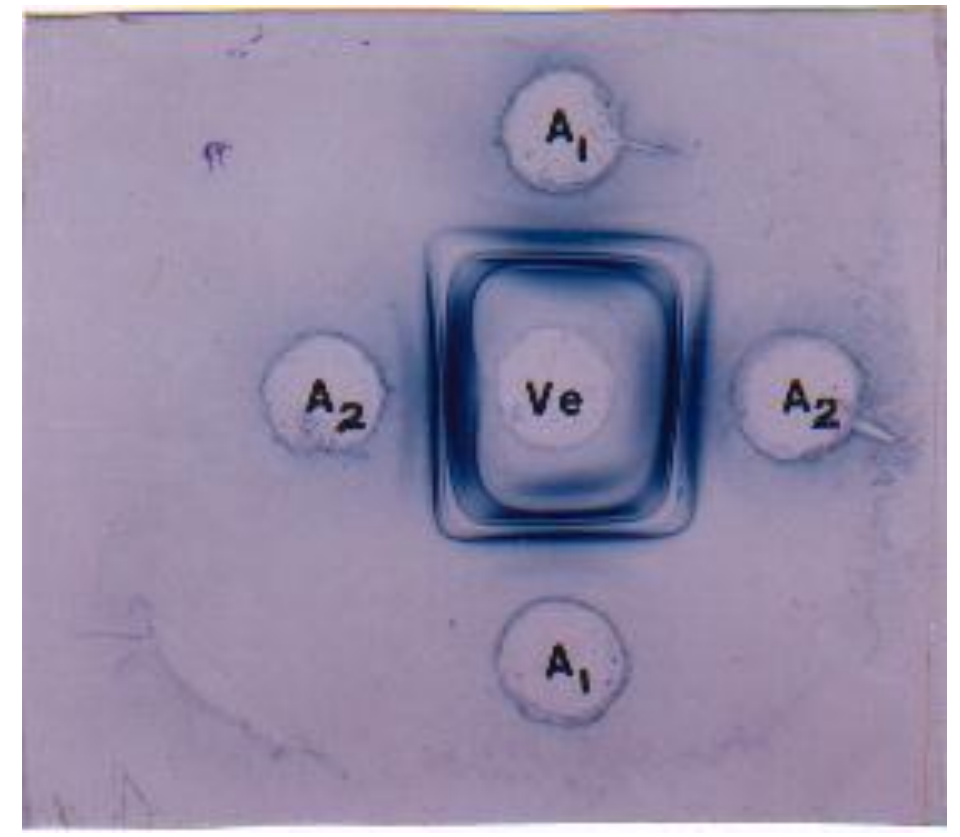

Fig. 1: Double immunodiffusion reaction of non-irradiated and $25 \mathrm{kGy}$ irradiated polyvalent antivenin with Naja haje venom $\mathrm{Ve}=$ Naja haje venom $(20 \mu \mathrm{l})$. $\mathrm{A}_{2}=25 \mathrm{kGy}$ irradiated antivenin.

$\mathrm{A}_{1}=$ Non-irradiated antivenin 


\section{Esmat A. Shaban \& Manar N. Hafez}

\section{Venom lethality:}

The i.p. $\mathrm{LD}_{50}$ for Cobra venom (Naja haje) was estimated to be $5 \mu \mathrm{g} / 20 \mathrm{gm}$ mouse as shown in Table I.

Table -I: Data for determination of $\mathrm{LD}_{50}$ of crude Naja haje venom following Spearman Karber method (WHO, 1981).

\begin{tabular}{|c|c|c|c|}
\hline $\begin{array}{c}\text { Dose } \\
\mu \mathrm{g} / \mathrm{Kg}\end{array}$ & Log Dose & $\begin{array}{c}\text { Number of animals injected } \\
\text { with each dose }\end{array}$ & Number of dead animals \\
\hline 157.39 & 2.197 & 6 & 0 \\
198.152 & 2.297 & 6 & 2 \\
249.459 & 2.397 & 6 & 4 \\
314.05 & 2.497 & 6 & 3 \\
395.36 & 2.597 & 6 & 5 \\
497.74 & 2.697 & 6 & 6 \\
\hline
\end{tabular}

$=2.697+1 / 2 \times 01-0.1 \frac{(2+4+3+5+6)}{6}=2.414$

Variance $\left(V_{m}\right)=\frac{d^{2}}{N^{2}(N-1)} \sum r_{1}\left(N-r_{1}\right)$

$=\frac{(0.1)^{2}}{36 \times 5} \times[2 \times 4+4 \times 2+3 \times 3+5 \times 1+6 \times 0]$

$=\frac{(0.1)^{2}}{36 \times 5}(30)=0.000166 \quad$ S. E. $=\sqrt{0.000166}=0.04082$

$95 \%$ fiducial limits of $\mathrm{m}=2.414 \pm 1.96 \times 0.04082$

$=2.414 \pm 0.00800 \quad=2.49-2.335$

$\therefore \mathrm{LD}_{50}=$ Antilog of $2.414=259.417 \mu \mathrm{g} / \mathrm{kg}$ (i.e. $5 \mu \mathrm{g} / 20$ gm mouse) with 95 percent fiducial limits of 309.029 and $215.774 \mu \mathrm{g} / \mathrm{kg}$ 
Table (II): Effect of Egyptian Cobra (Naja haje) venom and mixtures of non-irradiated and 25 kGy gamma-irradiated Egyptian polyvalent antivenin on some biochemical indices, in adult male rats. The data are presented as means \pm S.E.

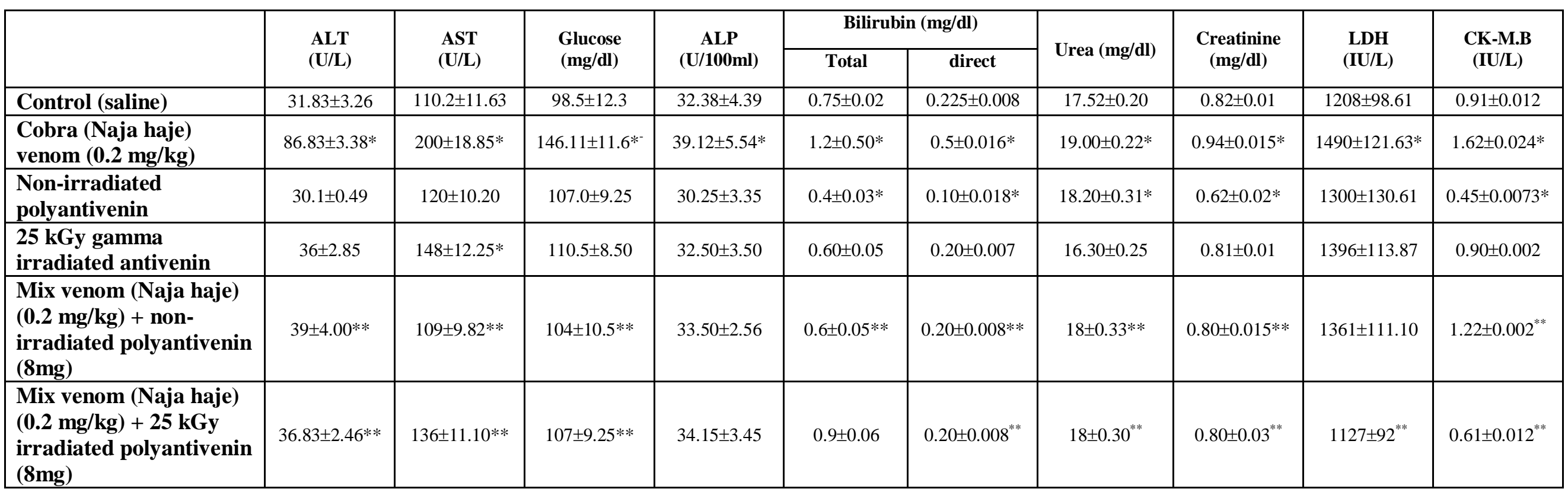

$\mathrm{n}=6$ male rats

Mix = mixture of venom and polyantivenin. $(0.2 \mathrm{mg} / \mathrm{kg})$ venom and $8 \mathrm{mg}$ antivenin incubated at $37^{\circ} \mathrm{C}$ for one hour and injected interperitoneally.

The degree of freedom is $\mathrm{n}_{1}+\mathrm{n}_{2}-2$

* Significant difference at $\mathrm{P} \leq 0.05$, compared to control group.

** Significant difference at $\mathrm{P} \leq 0.05$, compared to venom treated group. 


\section{Esmat A. Shaban \& Manar N. Hafez}

\section{Neutralization of venom lethal effect:}

The i.p. $\mathrm{LD}_{50}$ for Cobra venom (Naja haje) was estimated to be $5 \mu \mathrm{g} / 20 \mathrm{gm}$ mouse. The neutralization ability of both nonirradiated and $25 \mathrm{kGy}$ gamma-irradiated polyantivenin was the same against a dose of the venom $\left(2.5 \mathrm{LD}_{50}\right.$ i.e. $12.5 \mu \mathrm{g} / 20 \mathrm{gm}$ mouse). The minimal protective dose of the polyantivenin (irradiated or non-irradiated) was calculated to be $16000 \mu \mathrm{g} / 20 \mathrm{gm}$ mouse.

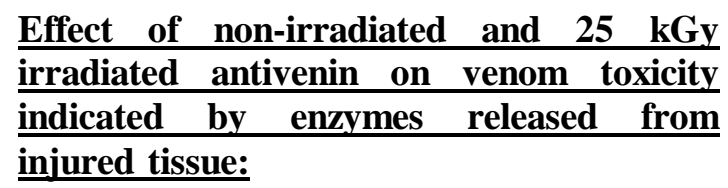

The serum biochemical indices, glucose, ALT, AST, bilirubin (direct and total), alkaline phosphatase (ALP), LDH, CK-MB, urea and creatinine were evaluated 24hr after i.p. injection of Cobra venom and mixture of venom and polyantivenin (nonirradiated or $25 \mathrm{kGy}$ irradiated) in the different groups of rats. The results on biochemical indices are given in Table (II). As shown, the i.p. injection of a sublethal dose of the venom $(0.2 \mathrm{mg} / \mathrm{kg})$ in rats induced a significant elevation in the activities of aminotransferases, glucose, alkaline phosphatase, total and direct bilirubin, urea, creatinine, CK-MB and LDH as compared to normal control values $(\mathrm{P} \leq$ $0.05)$.

Incubation of the same venom dose $(0.2 \mathrm{mg} / \mathrm{kg})$ together with $8 \mathrm{mg}$ of each polyvalent antivenin ( non-irradiated or irradiated ) at $37^{\circ} \mathrm{C}$ for $1 \mathrm{hr}$ before i.p. injection produced significant reduction in the values of AST, ALT, and the levels of the other parameters. However, this reduction was not sufficient to make their level reach the normal control levels.

\section{Histological Results:}

\section{1- Liver:}

\section{a)- Control group:}

The normal rat liver was divided into classic hepatic lobules formed of radially arranged cords of liver cells that radiate from the central vein to the periphery of the lobule. The cell cords were separated by narrow sinusoids lined by endothelial cells and Von Kupffer cells (Fig. 2).

\section{b)- Venom-injected group;}

Microscopic examination of the liver of rats excised following venom injection at a dose of $0.2 \mathrm{mg} / \mathrm{kg}$ had apparently revealed dilated and congested sinusoidal spaces infiltrated with inflammatory cells and haemorrhagic areas (Fig.3). Moreover, engorged and dilated hepatic portal vein in addition to vacuolar degeneration of many of hepatocytes and scattered necrotic areas with some pyknotic and karyolytic nuclei were also seen (Fig. 4).

c)- Mixture of venom and antivenin (nonirradiated or irradiated) injected groups:

Signs of improvement could be detected in the livers of rats injected with mixture of venom $(0.2 \mathrm{mg} / \mathrm{kg})$ and nonirradiated or $25 \mathrm{kGy}$ gamma-irradiated antivenin (8mg). Normal architecture of hepatic cords and disappearance of cytoplasmic vacuolation were observed, while slight dilatation of sinusoidal spaces and some congestion of hepatic portal veins with inflammatory cellular aggregations around the portal areas were still detected (Figs. $5 \& 6$ ).

\section{2-Spleen:}

\section{a)- Control group:}

The spleen of the control rat was formed of stroma of connective tissue and parenchyma. The parenchyma was formed of lymphoid tissue composed of white and red pulps. The white pulp was composed of central arteriole with aggregation of lymphoid tissue around. The red pulp was formed of vascular sinuses filled with blood cells (Fig. 7).

\section{b)- Venom-injected group:}

Examination of the spleen of rats injected with venom at a dose of $0.2 \mathrm{mg} / \mathrm{kg}$ displayed highly reduced white pulps with ill-defined outlines. Subcapsular sinuses were dilated and vacuolar appearance of the ground cytoplasm was observed. Haemorrhage in the sub capsular zone and 
red pulps in addition to signs of fibrosis and extravasation of blood could be noticed (Figs. $8 \& 9)$.

c)- Mixture of venom and antivenin (nonirradiated or irradiated) injected groups:

Spleens of rats injected with mixture of venom and non-irradiated or gammairradiated antivenin revealed an obvious manifestation of recovery of the parenchymal cells (white and red pulps). The lesions were apparently less evident, where areas of spleen have the normal architectural pattern inspite of mild reduction of white pulp with thickened wall of central arteriole as well as dilated and congested sinusoidal spaces of the red pulp (Figs. 10, $11 \& 12$ ).

\section{3-Heart:}

\section{a)- Control group:}

Normal appearance of cardiac tissues could be obsrved in Fig . (13) In this figure, longitudinal section of cardiac muscle illustrating the variable diameter of the fibers and the central position of their nuclei. The ends of the fibers are split longitudinally into a small number of branches the end of which abut onto similar branches of adjacent cells giving the impression of a continous threedimensional cytoplasmic network.

\section{b)- Venom-injected group:}

Heart of rats injected with venom at a dose of $0.2 \mathrm{mg} / \mathrm{kg}$ exhibited highly degenerated muscle fibers with loss of striations. Also massive extended haemorrhagic areas were apparently seen (Figs. $14 \& 15$ ).

c)- Mixture of venom and antivenin (nonirradiated or irradiated) injected groups:

Histological pictures of the heart of rats injected with a mixture of venom and nonirradiated or $25 \mathrm{kGy}$ irradiated antivenin showed restoration of the characteristic myocardium appearance, but some areas showed degenerative changes together with extravasated blood cells inbetween the myocardial bundles (Figs. $16 \&$ 17) 

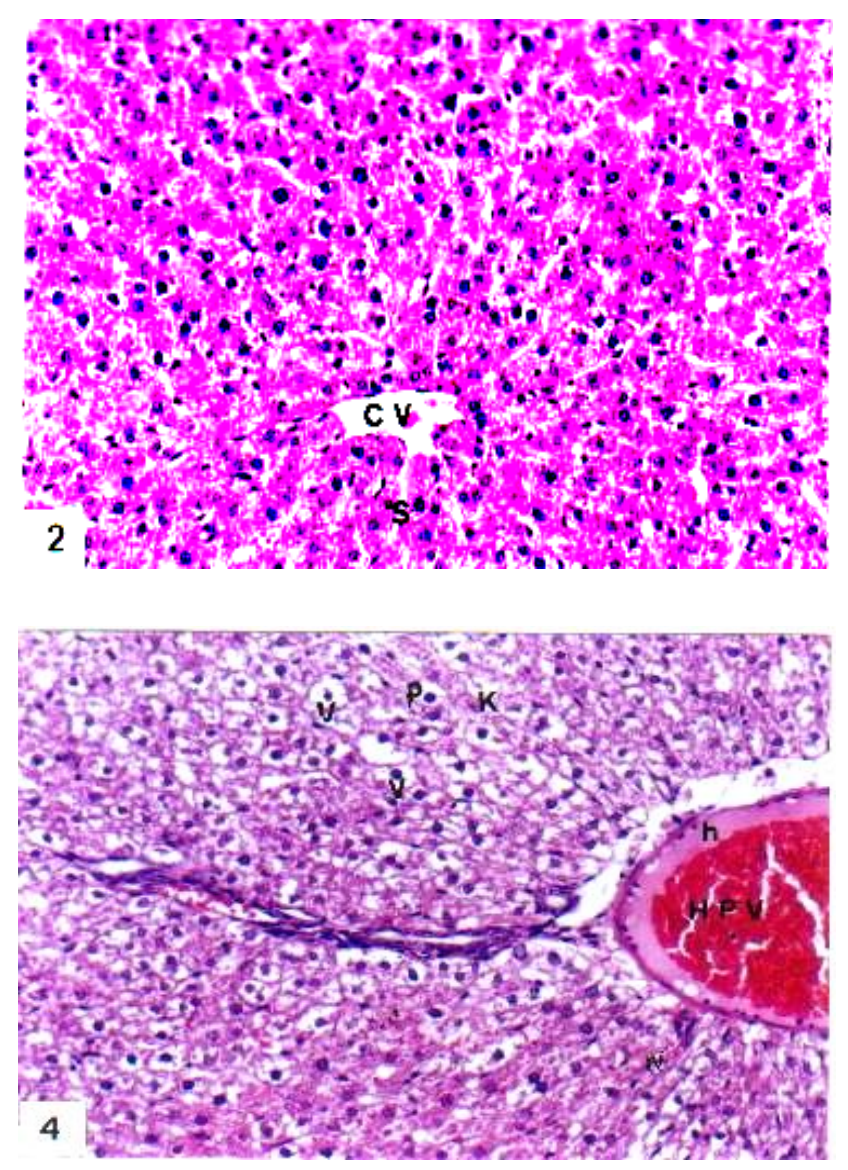
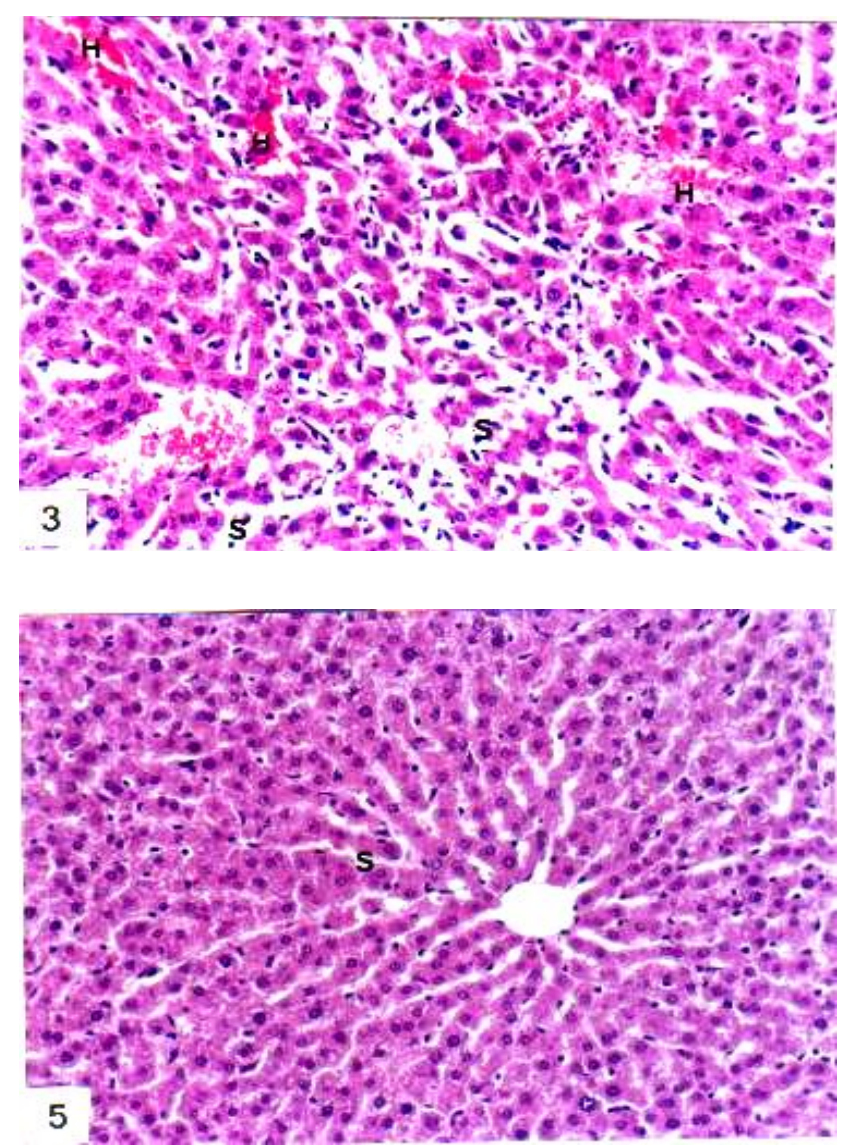

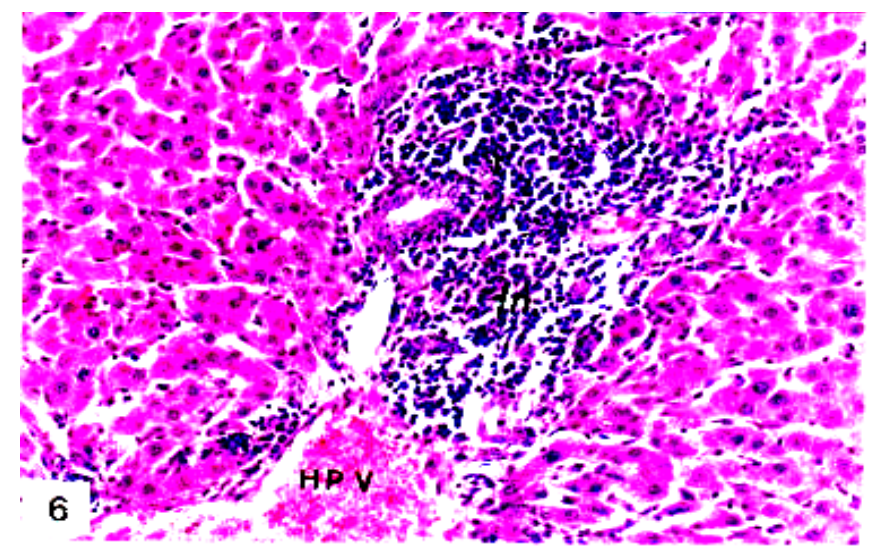

Fig. 2: Section in the liver of a control rat showing liver cords radiating from the central vein (C.V.) and separated by blood sinusoids ( $\mathrm{S}$ ).

(Hx. \& E. ; X 200).

Fig. 3: Section of a rat liver injected with venom showing dilated and congested blood sinusoids (S) distended by inflammatory cells and haemorrhagic $(\mathrm{H})$ areas.

(Hx. \& E. ; X 200).

Fig. 4: Another section of a rat liver injected with venom showing markedly dilated and engorged hepatic portal vein (H.P.V.) lined by a layer of dense hyaline (h). Vacuolated hepatocytes (V) and evidence of necrotic areas with some pyknotic $(\mathbf{P})$ and Karyolytic $(\mathrm{K})$ nuclei are also seen.

(Hx. \& E. ; X 200).

Fig. 5: Section in the liver of a rat injected with a mixture of venom and non-irradiated antivenin showing marked improvement of hepatocytes with little dilated sinusoidal spaces (S).

(Hx. \& E. ; X 200).

Fig. 6: Section in the liver of a rat injected with a mixture of venom and gamma-irradiated antivenin showing obvious recovery in hepatic cells. However, dilated and congested hepatic portal vein (H.P.V.) together with inflammatory cellular aggregation (In) are still observed.

(Hx. \& E. ; X 200). 
Ability of Gamma-Irradiated Polyvalent Antivenin.......
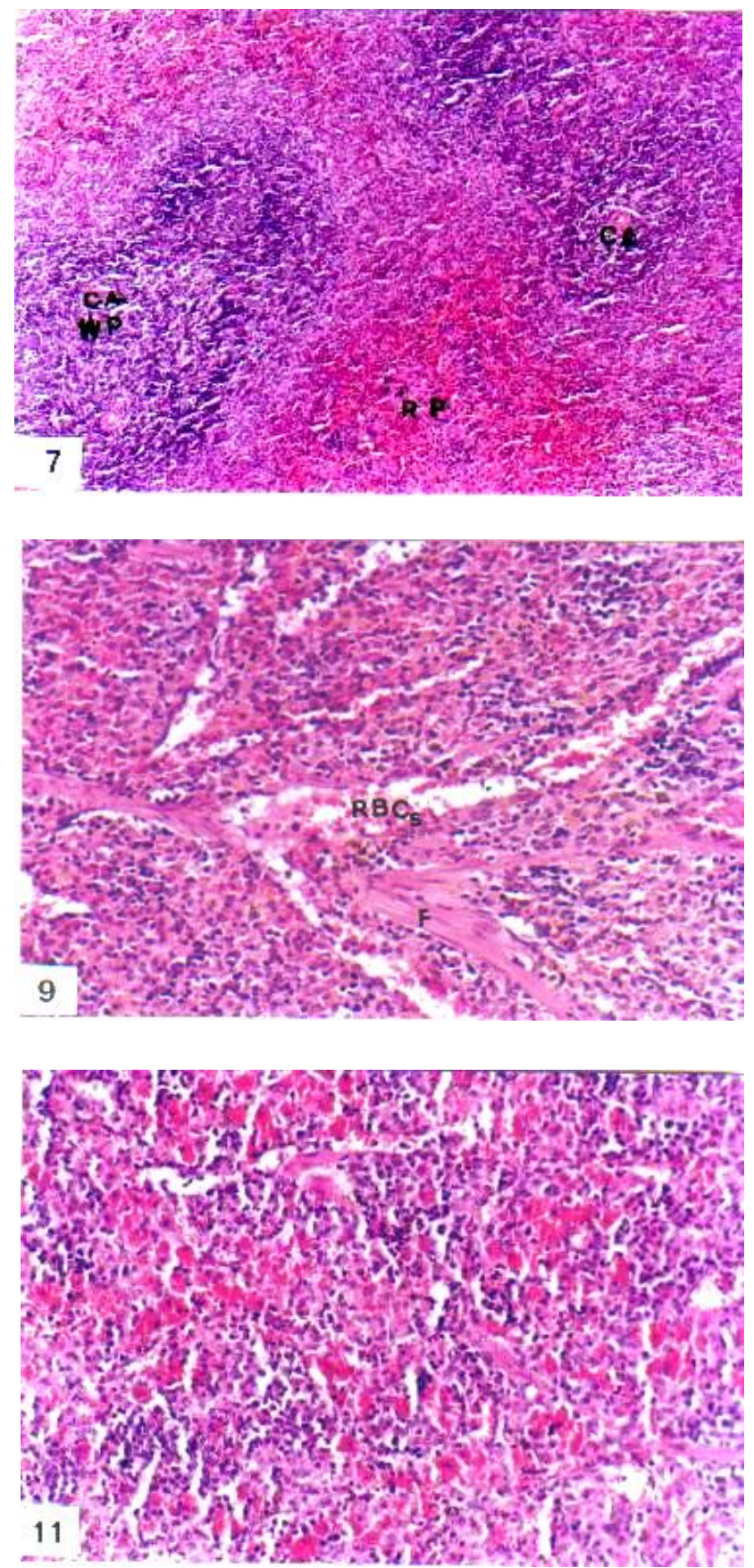
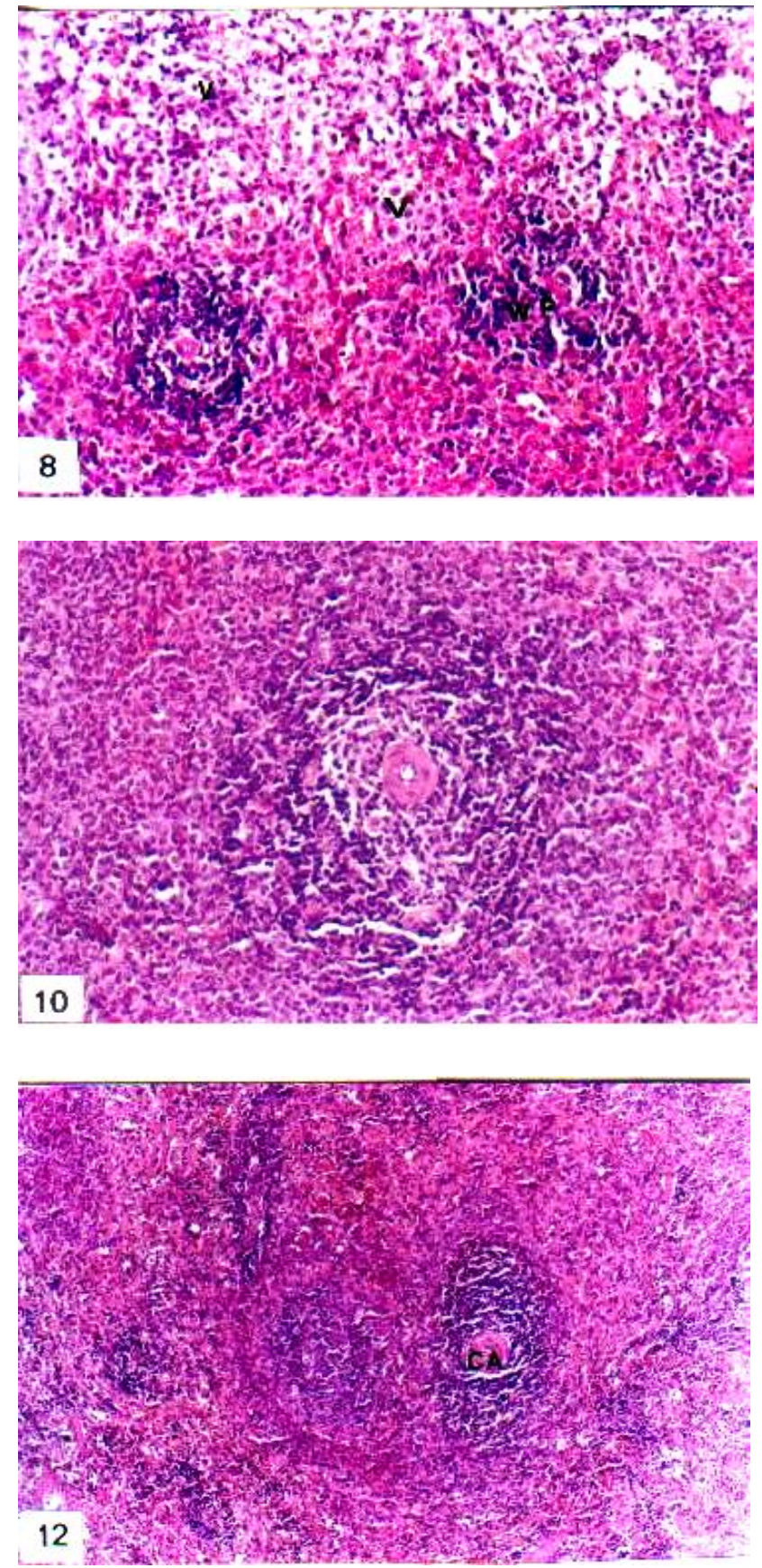


\section{Esmat A. Shaban \& Manar N. Hafez}

Fig. 7: Section in the spleen of a control rat showing splenic elongated white pulp (W.P.) with central arteriole (C.A.) and red pulp (R. P.) outside having blood sinusoids.

(Hx. \& E. ; X 100).

Fig. 8: Section in the spleen of a rat injected with venom showing small diffuse white pulp (W.P.) with ill-defined boundaries in addition to vacuolar appearance $(\mathrm{V})$ in the ground cytoplasm.

(Hx. \& E. ; X 200).

Fig. 9: Another part of a section in the spleen of a rat injected with venom showing signs of fibroplasia (F) as well as extravasated red blood cells (RBCs) extended to infiltrate the widened sinusoids.

(Hx. \& E. ; X 200).

Fig. 10: Section in the spleen of a rat injected with a mixture of venom and non-irradiated antivenin showing remarkable recovery in white and red pulps.

(Hx. \& E. ; X 200).

Fig. 11: Another section in the spleen of a rat injected with a mixture of venom and non-irradiated antivenin showing congested red pulps and the cytoplasm acquired mild hyaline appearance.

(Hx. \& E. ; X 200).

Fig. 12: Section in the spleen of a rat injected with a mixture of venom and gamma-irradiated antivenin showing areas of healthy tissue with little thickened central arteriole (C.A.) and mild reduction in white pulp (W.P.).

(Hx. \& E. ; X 100).
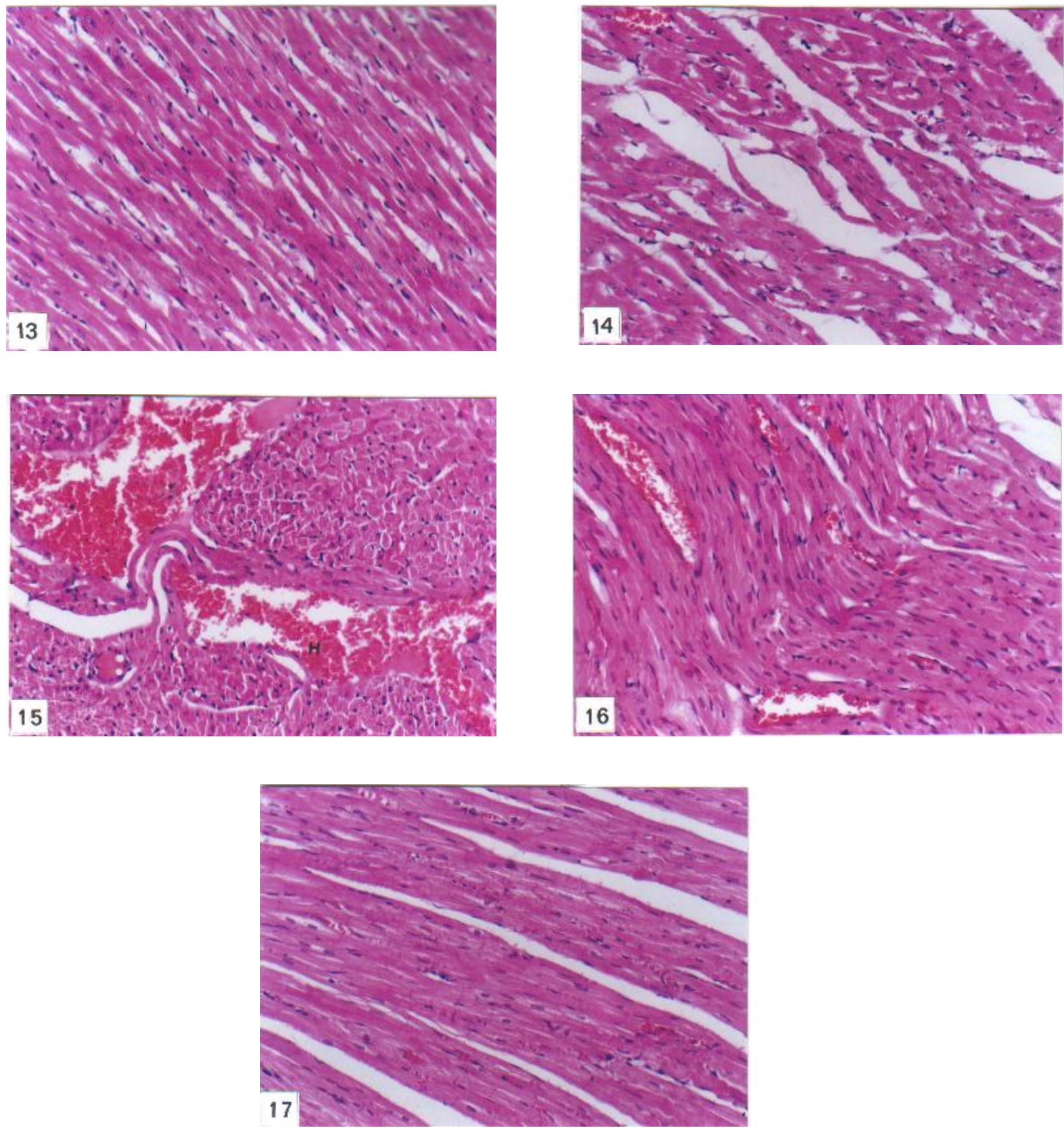
Fig. 13: Longitudinal section of the myocardium of untreated control rat.

(Hx. \& E. ; X 200).

Fig. 14: Section in the heart of a rat injected with venom showing degenerated muscle fibers with loss of striations.

(Hx. \& E. ; X 200).

Fig. 15: Another section of the myocardium of a rat injected with venom showing severely extensive haemorrhagic areas.

(Hx. \& E. ; X 200).

Fig. 16: Heart section of a rat injected with a mixture of venom and non-irradiated antivenin showing obvious return to normal myocardial appearance.

(Hx. \& E. ; X 200).

Fig. 17: Section in the heart of a rat injected with a mixture of venom and gamma-irradiated antivenin showing restoration of the characteristic appearance of cardiac muscle with minimal extravasation of blood cells inbetween the myocardial bundles.

(Hx. \& E. ; X 200).

\section{Discussion}

The results obtained in the present study showed that $25 \mathrm{kGy}$ gamma-irradiated lyophilized polyvalent antivenin did not lead to any inactivation in its immunoglobulins. Immunodiffusion study of the irradiated antivenin showed strong reaction and revealed the same precipitin bands pattern with the tested venom exactly as the nonirradiated antivenin. Also, irradiation did not decrease the antilethal power of antivenin, $16000 \mu \mathrm{g}$ of irradiated or non-irradiated antivenin was capable to neutralize 2.5 LD50 of the Egyptian Cobra (Naja haje) venom. No increment in the dose of irradiated antivenin was needed to neutralize an identical quantity of the venom. These data therefore, showed that gamma-irradiation did not change the antivenin immunoglobulins power. Such data obtained in vitro could be extrapolated to in vivo as Nishikawa et al. (1994) indicated that the antibodies present in the antivenin combine with venom components as measured in vitro by Elisa assay, and neutralize their lethal effects in vivo.

Venom from Cobra (Naja haje) contains several kinds of toxic proteins. The most lethal are the $\alpha$-neurotoxins, which are single-chain proteins of about 60 or 70 residues. These toxins bind to nicotinic acetycholine receptors, and they cause death by paralyzing respiratory muscles. Other active components of the venom that might be also lethal mostly as a result of tissue damage are phospholipases, proteases, cardiotoxins, coagulants, anticoagulants and hemolysins (Alan, 1991). Egyptian Naja haje venom is highly lethal like other elapid snake venoms due to its content of neurotoxin, which kills by paralyzing respiratory muscles in few minutes. Neutralization of this lethal fraction represents the primary goal of antivenin and in our study immunoglobulins conveying this function were not affected by a sterilizing dose of gamma-irradiation (25 kGy).

The effects of Naja haje venom on some biochemical parameters were also studied. The i.p. injected venom in a sublethal dose of $0.2 \mathrm{mg} / \mathrm{kg}$ into rats increased serum glucose significantly. Also, a significant hyperglycemic effect was obtained as a result of Cerastes cerastes venom (Omran et al. 1997 and Metawie et al., 1999). The latters recorded that this action of the venom may be a primary action on insulin secretion and / or secondarily to stimulation of the adrenal medulla and release of epinephrine. These findings are also in agreement with those reported by Mohamed et al. (1972); Hodhod et al. (1989) and Saleh, (1992) using different snake venoms.

Enzymes are present throughout the body and their measurement can provide valuable diagnostic information. The present work showed enormous increase in ALT and AST in rats injected with venom. Similar observation was reported by Sant et al. (1974) and Temb et al. (1975) using Echis Carinatus snake and Mohamed et al. (1981) using Egyptian Cobra envenomation. They attributed the increase in enzyme activity to a hepatotoxic agent in the venom of such snakes. Mohamed et al. (1974 a \& b) showed that hepatocytes of envenomated rats 


\section{Esmat A. Shaban \& Manar N. Hafez}

revealed marked histopathological changes. In this respect, Tietz (1983), mentioned that although the tissues of the kidney, heart and skeletal muscles have significant amounts of ALT, liver damage can be fairly assumed when serum ALT levels increase because it is more specific to liver cells. Moreover, Tresseler (1988) mentioned that elevation in serum AST results from conditions causing injury to cardiac muscle.

The rapid rise in ALT and AST activities recorded in the present study $24 \mathrm{hr}$ after venom envenomation may be attributed to severe injuries and necrosis of hepatocytes as well as to a nephrotoxic action of the venom as reported by Abdel Nabi (1993). Also, Kadryov (1987) and Omran and Abdel Rahman (1992), reported that lethal and sublethal doses of venom were capable of stimulating stress reactions. Cortisol and catecholamines are the main hormones released in response to stress, and increased levels of these hormones in victims circulation may cause severe damage in many vital organs proportional to the dose of the venom and the elapsid time. Organ damage is followed by an increase in levels of ALT , AST and ALP (Omran et al. 1997). Rahmy and Hemmaid (2000 \& 2001) reported that Cobra venom induced a hepatotoxic action reflected by alteration in the histlogical and histochemical patterns of the hepatic tissues. These alterations are initiated at early stages of envenomation and could indicate a disturbance in the functional activities of the liver during envenomation.

The significant increase in serum urea and creatinine levels in the present study may be due to the nephrotoxic effect of Egyptian Cobra (Naja haje). This was in agreement with the findings of Rahmy et al. (1992 \& 1995b) and Yaguchi et al. (1996). They mentioned that serious renal complications in case of Naja haje and Cerastes cerastes envenomation lead to impairment of the excretory function of the kidney. Significant elevation in serum urea recorded in this work may be also attributed to an increase of nitrogen retention and / or due to corrupted renal function (Abdel Nabi, 1993).

The antivenin, either non-irradiated or 25 kGy gamma-irradiated, was highly effective in neutralizing many of the biochemical effects of the venom. The hyperglycemia observed after $24 \mathrm{hr}$ of the venom injection in rats, was prevented by incubating the venom with the specific antivenin (non-irradiated and $25 \mathrm{kGy}$ irradiated) for one hour showing that, the hyperglycemic factors (s) were antigenic and inactivated by the specific antivenin (Ismail et al., 1977). The exposure of the antivenin to a sterilizing dose $(25 \mathrm{kGy})$ did not affect these antigenic properties. Also, the nonirradiated and $25 \mathrm{kGy}$ gamma-irradiated antivenin neutralized the significant increase in the serum urea and creatinine levels, caused venom injection in rats.

Egyptian Cobra venom is known for its cardiotoxic and neutrotoxic activity (Casarett and Doull, 1975). Enzyme markers of such injured tissues (AST, ALT, LDH and CKMB) by Cobra envenomation were all significantly reduced when the venom was incubated with antivenin (non irradiated and $25 \mathrm{kGy}$ irradiated) prior to injection in rats. This indicate that the protective action of antivenin against toxic ingredients of the venom was not influenced or decreased by gamma-irradiation in the dose used (25 kGy). This agrees with the finding of Gutierrez et al. (1987) who reported that the antivenin contains antibodies capable of preventing and neutralizing the toxic and enzymatic activities of the venom.

It is interesting to note that, the neutralizing capacities of non-irradiated and $25 \mathrm{kGy}$ irradiated antivenin were high. They neutralize both the lethal and the biological effects of the venom almost to the same extent. It is suggested that the antivenin in lyophilized form after exposure to the sterilizing dose $(25 \mathrm{kGy})$ was not degraded. This does not exclude the possibility that it was degraded but the degree of degradation was not high enough to affect the neutralizing capacities of the antivenin.

The histopathological effects of Cobra venom showed that the livers of rats injected with venom in a sublethal dose $(0.2 \mathrm{mg} / \mathrm{kg})$ exhibited dilated and congested blood vessels and sinusoids which were infiltrated with inflammatory cells as well as haemorrhagic areas. Similar findings were obtained by Mohamed et al. (1974 a\&b); Hassan et al. (1986) and Alan (1991), who attributed these changes to a hepatotoxic effect of the venom and it is more likely to be described as a proinflammatory action of some snake toxins. 
According to Jeremy et al. (1990), the progressive dilatation of blood vessels could be considered as a reactive change that may be related to an inhibitory effect on vascular smooth muscles which induced relaxation and consequent vasodilatation. Meanwhile, the observed inflammatory cellular infiltration may be a secondary effect to the engorgement of blood sinusoids (Mikhalidis and Dandona, 1990). Furthermore, Walter and Israel (1987) proved that the presence of infiltrating cells was a feature of inflammation. In this concern, Grassso et al. (1974) reported that the abundance of inflammatory cells results partially from reduced energy production as a result of tissue damage and partially by a reduction of some essential respiratory oxidative enzymes under different pathological conditions.

Vacuolar degeneration of most hepatocytes and cell necrosis were also seen under the effect of the venom. A number of necrotic cells showed pyknotic nuclei while others were devoid of their nuclei. Identical necrotic changes in liver were observed by Hanafy et al. (1999) in rats injected with 0.2 $\mathrm{mg} / \mathrm{kg}$ of Cerastes cerastes snake venom.

Bhagwat and Deodhar (1968) suggested that the degenerative effects appearing in the hepatic cells are most probably due to the intercellular oedema or hydropic changes together with increased glycogen and lipid contents. These are in turn due to the metabolic disturbance and inhibition of protein synthesis. Also, as reported by Reynolds and Martindale (1993), the vacuolated cytoplasm indicating that the hepatocytes are undergoing death. Therefore, the localized areas of necrosis showed in this study may be the result of a direct action of the snake venom or secondary to vascular disturbances and severe degeneration.

The effect of the venom on spleen tissue in the present work revealed small diffuse white pulps, dilated sinuses and vacuolated cytoplasm. Extensive haemorrhage and fibrosis in the subcapsular zone and red pulp were also seen. The same observations were recorded by Mohamed et al. (1980) using guinea pigs. Also, gross microscopic lesions produced in spleen by snake venom have been reported by Taube and Essex (1937) and Mohamed et al. (1974a). Decreased size of white pulps in this study may be due to the immunosuppressive effect of the venom on the lymphocytes present in the white pulps. According to Mohamed et al. (1975 \& 1978), lymphocytic depletion detected after lethal doses of Naja haje venom, may be due to migration of lymphocytes from lymph nodes and spleen to foci of lymphocytic infiltration as kidneys, livers and suprarenals, or may be an effect of stress. Tu (1991) and Omran \& Abdel Rahman (1992) reported that lethal and sublethal doses of snake venom were able to stimulate stress reactions.

It is well known that snake venom often causes muscle damage. From the present study, it was shown that the injection of Naja haje venom produced severe degeneration of muscle fibers and loss of striations. Also, haemorrhage and extravasated red blood cells were seen inbetween the myocardial bundles. Similar results were recorded by $\mathrm{Tu}$ and Homma (1970); Rahmy et al. (1995a \& b) and Hanafy et al. (1999). In the present work the haemorrhage observed inbetween the cardiac muscles of animals receiving the venom may be due to increased intravascular tension or venous congestion (Willoughly, 1960). Rahmy et al. (1991) reported that the crude venom of Cerastes cerastes induced severe haemorrhage as well as extensive myofilament damage at the electron microscopic level. Visual observation of the site of snake bite, often showed severe muscle damage because of massive local haemorrhage.

On the other hand, the present findings showed that the treatment with a mixture of the venom $(0.2 \mathrm{mg} / \mathrm{kg})$ and antivenin $(8 \mathrm{mg})$ either non-irradiated or $25 \mathrm{kGy}$ gammairradiated produced an obvious improvement of hepatocytes against the highly toxic effect of the venom. The histological pictures revealed the disappearance of cytoplasmic vacuolation and more regular hepatic cords. However, inflammatory cellular aggregations together with some congestion and dilatation of blood vessels and sinusoids were still observed. The lymphocytic infiltration may be considered as a defense mechanism of the liver against the injurous toxic effect of the venom. As reported by Leeson et al. (1988), the lymphocytes play an important role in both humoral antibody and cell-mediated immune-responses. In spleen, a noticeable recovery of the parenchymal cells of both white and red pulps was well marked. The 


\section{Esmat A. Shaban \& Manar N. Hafez}

lesions were apparently less in severity, where areas of spleen appeared to be of healthy tissue or showed mild degenerative parenchyma and thickened central arteriole. Walter and Israel (1987) reported that the thickening central arteriole and congestion of the red pulp may be secondary to the developed portal hypertension in the liver. Regarding the heart, evidence of restoration of the characteristic myocardium appearance was obtained. But nevertheless, dilated blood vessels and extravasated blood cells inbetween the myocardial bundles were still detected. Thus, it can be deduced that the treatment with a mixture of venom and antivenin (non-irradiated or $25 \mathrm{kGy}$ gammairradiated) markedly reduced the degree of damage induced by the venom in both liver and spleen or even the heart which appeared more or less normal except for minor abnormalities that were still present.

From the above results, it can be concluded that in severe envenomation, there may be remaining symptoms and problems for a long time. The follow-up is of academic interest. As relatively few patients seem to be brought back for medical evaluation after a snake bite, the knowledge of long lasting and late symptoms is very incomplete. Therefore, to be able to judge about the whole problem of snake envenoming and its complications, and to assess the efficacy of treatment given, a better and more systematic follow-up seems indispensable.

\section{References:}

1. Abdel-Nabi, I. M. (1993): Effect of crude Cerastes cerastes venom and fraction $\mathrm{B}$ on the clinical biochemical parameters of white rat. J. Egypt. Ger. Soc. Zool., 10 : 315-326.

2. Alan, L. H. (1991): Cardiotoxins from Cobra venoms In: "Handbook of natural toxins reptile venoms and toxins." P.85 (Antony T. Tu, Ed.), Marcel Dekker, Inc., New York, Basel, Hong Kong.

3. Anon, U. V. (1970): Method for estimation of lactate dehydrogenase in serum and tissue extracts. Z. Klin. Chem., U. Klin. Bioch., 8: 658.

4. Bancroft, H. (1963): Introduction to biostatistics, $5^{\text {th }}$ ed., Hoeber Medical Division, Harper and Row Publishers.

5. Bhagwat, A. G. and Deodhar, S. D. (1968): Experimental hepatic injury produced in the rabbit by glucocorticoids. Arch. Pathol., 85: 346-352.

6. Bolanas, R. and Cerdas, L. (1980): Production control de Sueros antiofidicos en Costa Rica Boln of Saint Pan 88: 189.

7. Bowers, L. D. and Wrong, E. T. (1980): Kinetic serum creatinine assay. Clin. Chem., 26: 555.

8. Casarett, L. J. and Doull, J. (1975): Toxicology: The basic science of poisons. pp, 486-470. New York, Toronto, London.

9. Chippaux, J. P. (1991): Production and use of snake antivenin. Handbook of Natural Toxins, Vol. 5, (A. T. Tu Ed.), Marcel Dekker, Inc. pp. 529-556, New York, Bazel, Hong Kong.

10. Doumos, B.T., Perry, B.W. and Sasse, E.A. (1973): J. Clin. Chem ., 19: 948. Coated from : Micro-analysis in medical biochemistry. $4^{\text {th }}$ ed., p.82, Landan .

11. Drury, R. A. and Wallington, E. A. (1980): General staining procedures. In: "Carleton's histological technique". $4^{\text {th }}$ ed. pp. 125-150.. Oxford Univ. Press. New York, Toronto.

12. Grasso, P.; Wright, M.; Gangolli, S. and Hedy, R. (1974): Liver response tests.IX: Cytopathological changes in the enlarged but histologically normal rat liver Cosmet Toxicol., 12: 341-350.

13. Gutierrez, J. M.; Avila, C.; Rojas, E. and Cerdas, L. (1988): An alternative in vitro method for testing the potency of the polyvalent antivenom produced in Costa Rica. Toxicon, 26: 411-413.

14. Gutierrez, J. M., Rojas, G. and Cerdas, L. (1987): Ability of a polyvalent antivenom to neutralize the venom of Lachesis muta melanocephala, a new Costa Rican subspecies of the bushmaster. Toxicon, 25: 713-720.

15. Hanafy, M. S.; Rahmy, N. A. and Abd ElKhalek, M. M. (1999): The dielectric properties of neutron irradiated snake venom and its pathological impact. Med. Biol., 44: 2343-2364.

16. Hassan, F. M.; El-Banhawy, M. A.; Mohaddal, M. E. and Rahmy, T. R. (1986): Lethality of pseudo Cerastes persicus field venom and the effect of its sublethal dose on the liver function of envenomated rats. Egypt. J. Biochem., 4: 120-148.

17. Harvey, A. L. (2000): Snake Toxins. In :'Intentional Encyclopedia of Pharmacology and Therapeutics". (Alan, L. Harvey, Ed.). p.73 New York, Oxfor, Toronta. Pergamon Press.

18. Hodhod, S.; Swelam, N.; Tash, F.; Ghoniem, K and Al-Asmar, M. F. (1989): Effect of Cerastes cerastes (Egyptian sand 
viper) venom on rat pancreas. Egypt. J. Biochem., 7: 19-38.

19. Ismail, M.; El-Khawad, A. and ElSeweidy, M. (1977): Hyperglycemic effect of scorpion (Androctonus amoreuxi, Aud. and Sav.) venom in rabbits. Abstracts of $\mathrm{XV}^{\text {th }}$ Congress of Pharmaceutical Science, Cairo, p., 98 .

20. Jeremy, J. V.; Mikhalidis, D. P. and Kopp, V. C. (1990): Differential inhibitory potencies of opiate drugs on smooth muscles. Eur. J. Pharmacol., 182: 83-89.

21. Kadryov, I. K. (1987): An electron microscope study of adrenal cortex in rats envenomated by middle Asian gurza venom (Viper lebtina). Toxicon, 16: 673.

22. King, P. R. and King, E. G. (1954): Practical. Clinical Biochemistry. (Varley H.; Gowenlock, A. H. and Bell, M. Eds.), $5^{\text {th }}$ ed., p., 891. William Heinmann Medical Books Ltd, London.

23. Lesson, T. S.; Lesson, C. R. and Paparo, A. A. (1988): Text Atlas of Histology. W. R. Saunders Co., Philadelphia, London, Toronto.

24. Lomonte, B. (1985): Oedema-forming activity of bushmaster (Lachesis muta stenophrys) and Central American rattlesnake (Crotalus durissus durissis) venoms and its neutralization by a polyvalent antivenom. Toxicon, 23: 173-176.

25. Metawie, R. A.; Abdel-Khalek, M. M.; Rahmy, N. A. and Hanafy, M. S. (1999): Effect of low doses of fast neutrons on some biophysical and biochemical changes in serum of rats exposed to irradiated snake venom. J. Egypt. Vet. Med. Assoc., 59: 1167-1192.

26. Mikhalidis, D. P. and Dandona, P. (1990): Opiates and smooth muscles. J. Pharmacol., 184: 84-88.

27. Mohamed, A. H.; Ahmed, S. and Beshir, S. R. (1980): Effect of Naja haje snake venom on guinea pig spleen and lymph nodes. Toxicon, 18: 374-380.

28. Mohamed, A. H.; Anwar, N. N. and Hanna, M. M. (1974a): Influence of hydrocortison on the microscopic changes produced by Naje nigricollis venom in kidney, liver and spleen. Toxicon, 12: 45-48.

29. Mohamed, A. H.; Foud, S.; El-Aasr, S. ; Salem, A. M.; Abdel-Aal, A.; AbdelBaset, A.; Hassan, A.; Zahran, F. and Abbas, N. (1981): Effect of several snake venoms on serum and tissue transaminase alkaline phosphatase and lactate dehydrogenase. Toxicon, 19: 605-609.

30. Mohamed, A. H.; Hanna, M. M. and Selim, R. (1972): The effect of Naja haje venom and its ionophoretic fraction on glucose metabolism. Toxicon, 10: 1-5.

31. Mohamed, A. H.; Saleh, A. M.; Ahmed, S. and Beshir, S. R. (1975): Histopathological and histochemical effects of Naja haje venom on kidney tissue of mice. Toxicon, 13: 409 .

32. Mohamed, A. H.; Saleh, A. M.; Ahmed, S. and Beshir, S. R. (1978): Histopathological effects of Naja haje snake venom and venom gland extract of the scorpion Buthus quinquestriatus on the liver, suprarenal gland and pancreas of mice. Toxicon, 16: 253.

33. Mohamed, A. H.; Saleh, A. M. and HaniAyobe, M. (1974b): Studies on Egyptian Cerastes cerastes antivenin. Toxicon, 12: 852-855.

34. Nishikawa, A. K.; Cancati, C. P.; Lima, M. L.; Dos Santos, M. C.; Kipnis, T. L.; Eickstesit, V. R.; Knysat, I., Da Silvo, M. H.; Nigashi, H. C. and Da Selva, W. D. (1994): Antigenic cross-reactivity among the venoms from several species of Brazilian scorpions. Toxicon, 32: 89-90.

35. Omran, M. A.; Abdel-Nabi, I. M. and ElNaggar, M. H. (1997): Serum biochemical and hormonal parameters for the toxic effects of Egyptian Cobra (Naja haje) envenomation. J. Nat. Toxins, 6: 69-83.

36. Omran, M. A. and Abdel Rahman, M. S. (1992): Effect of scorpion Leiurus quiquestriatus venom on the clinical chemistry parameters of the rat. Toxicol. Lett., 61: 99-109.

37. Ouchterlony, O and Nilsson, L. A. (1948): Immunodiffussion and immunoelectrophoresis, In: "Handbook of experimental immunology," pp. 1-19. War, D. M. Ed.,), Oxford, Rockwell Scientific puplications.

38. Patton, C. J. and Crowtch, S. R. (1977): Spectrophotometric and kinetics investigation of the berthelat reaction for the determination of ammonia, J. Anal. Chem., 49: 464.

39. Poctor, B. E. and Goldblith, S. A. (1953): Microbiological investigations of the lethal effects of various types of ionizing radiation. USA, EC reps. 7: 79.

40. Rahmy, T. R. and Hemmaid, K. Z. (2000): Histological and histochemical alteration in the liver following intramuscular injection with a sublethal dose of the Egyptian Cobra venom. J. Nat. Toxins, 9: 21-32.

41. Rahmy, T. R. and Hemmaid, K. Z. (2001): Prophylactic action of garlic on the histological and histochemical patterns of hepatic and gastric tissues in rats ingected with a snake venom. J. Nat. Toxins, 10: 137-165.

42. Rahmy, T. R.; Ramadan, R. A.; Farid, T. M. and El-Asmar, M. F. (1995a): Actions 


\section{Esmat A. Shaban \& Manar N. Hafez}

of Cobra venom on cardiac muscles of rats. J. Egypt. Ger. Soc. Zool., 17: 235-250.

43. Rahmy, T. R.; Ramadan, R. A.; Farid, T. M.; El-Asmar, M. F. (1995b): Renal lesions induced by Cobra envenomation. J. Egypt. Ger. Soc. Zool., 17 : 251-271.

44. Rahmy, T. R.; Tu, A. T.; El-Banhawy, M. A.; El-Asmar, M. F. and Hassan, F. M. (1991): Electron microscopic study of the effect of Egyptian sand viper (Cerastes cerastes) venom and its hemorrhagic toxin on muscle. J. of Wilderness Medicine, 2:714.

45. Rahmy, T. R.; Tu, A. T.; El-Banhawy, M.; El-Asmar, M. F. and Hassan, F. M. (1992): Cytopathological effect of Cerastes cerastes (Egyptian sand viper) venom and its hemorrhagic toxin on liver and kidney. An electron microscopic study. J. Nat., Toxins, $1: 45-58$.

46. Reitman, S. and Frankel, S. (1957): Determination of serum glutamic oxaloacetic and glutamic pyruvic transaminase. Am. J. Clin. Path., 28: 56.

47. Reynolds, J. and Martindale, E. (1993): The Extra Pharmacopoeia, $30^{\text {th }}$ ed., The pharmaceutical press, pp., 781-805, London.

48. Rojas, G.; Espinoza, M.; Lomonte, B. and Gutierrez, J. M. (1990): Effect of storage temperature on the stability of the liquid polyvalent antivenom produced in Costa Rica. Toxicon, 28: 101-105.

49. Saleh, S. R. (1992): Effect of snake venom on carbohydrate metabolism in rats. M. D. Thesis, Faculty of Medicine, Suez Canal University.

50. Sant, S. M.; Rembe, V. S.; Salgaonkar, D. S. and Purandar, N. M. (1974): Lesions produced by Echis carinatus venom in experimental animals. Postgrad. Med., 21: 36-47.

51. Shaban, E. A. (1990): Studies on impact of irradiation treatment on pharmacological responses of scorpion venom and antivenin serum. Ph.D Thesis, Faculty of Pharmacy, Alexandria University.
52. Taube, H. N. and Essex, H. E. (1937): Pathological changes in the tissues of the dog following injection of rattlesnake venom. Arch Pathol., 24: 43.

53. Temb, V. S.; Sant, S. M. and Purandare, N. M. (1975): A clinco-pathologic study of sanke bite cases.J.Postgrad. Med., 21: 36-47.

54. Tietz, G. W. (1983): Clinical guide to laboratory tests. Saunders, Philadelphia.

55. Tresseler, K. M. (1988): Clinical laboratory and diagnostic tests $2^{\text {nd }}$ ed., pp., 116-130. Englewood Cliffs, NJ: Prentice-Hall.

56. Trinder, P. (1969): Determination of serum glucose. Am. Clin. Biochem., 6: 24-27.

57. Tu, A. T. (1991): Tissue damaging effects by snake venom haemorrhage and myonecrosis. Handbook of Natural Toxins, Vol. 5, pp. 297-347. A. T. Tu Ed., New York: Dekker.

58. Tu, A. T. and Homma, M. (1970): Toxicologic study of snake venom from Costa Rica. Toxicol. Appl. Pharmacol., 16: 73-78.

59. Tumanyan,M. A. (1973): Radiosterilization of prepared vaccines. In: "Manual on Radiation Sterilization of Medical and Biological Materials". Tech. Rep. Series M.149, pp. 291-292.

60. Walter, J. B. and Israel, M. S. (1987): Cells response to injury. In: "General Pathology". Chap. 4, p., 57. $6^{\text {th }}$ ed., Churchill Livingstone, Edinburgh, London.

61. WHO (1981): World Health Organization, Progress in the characterization of venom and standardization of venoms and antivenins. WHO Offset publication N., 58.

62. Willoughly, D. A. (1960): Pharmacological aspects of the vascular permeability changes in the rats intestine following abdominal radiation. Br. J. Radiol., 33: 515-519.

63. Yaguchi, T.; Ueda, Y. and Ishitobi, F., (1996): Clincopathological study of the renal damage caused by mamushi snake (Agkistrodan biomhoffi) venom and effects of cepharanthin against it in mice. Dokkyo. Igakks Zasshi, 11: 127-141. 


\section{فاعلية المصل المشعع جاميا فى معادلة سمية الكوبرا المصرية}

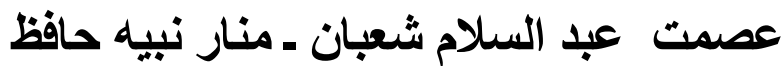

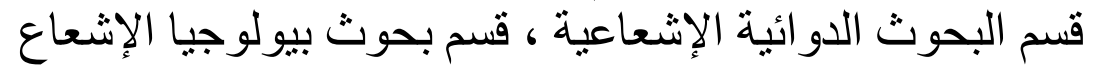

المركز القومى لبحوث وتكنولوجيا الإشعاع ـ هيئة الطاقة الذرية ـ القاهرة

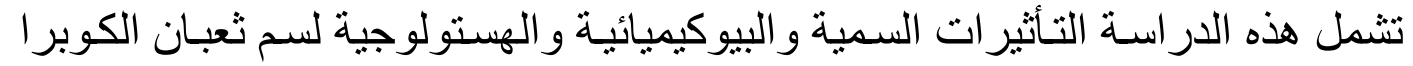

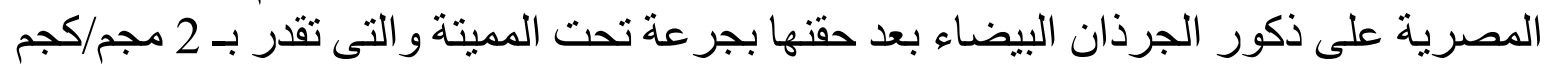

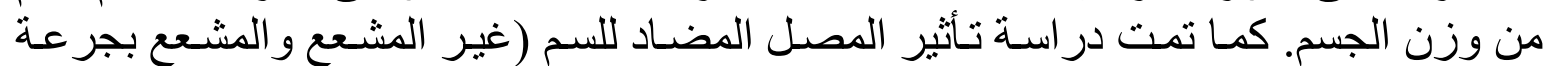

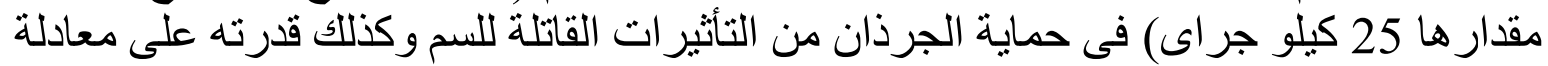

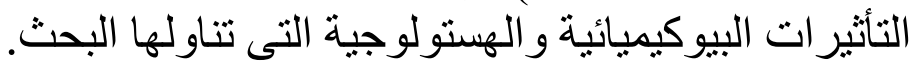

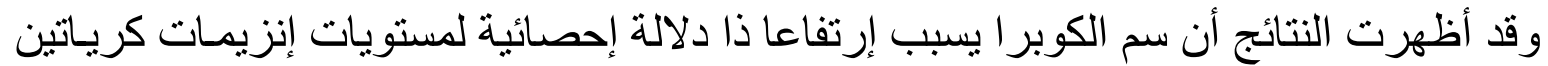

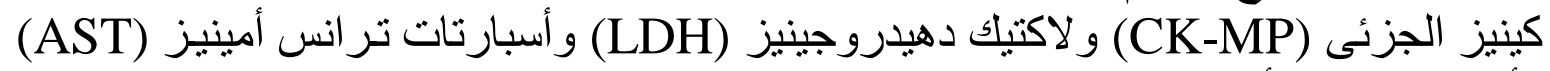

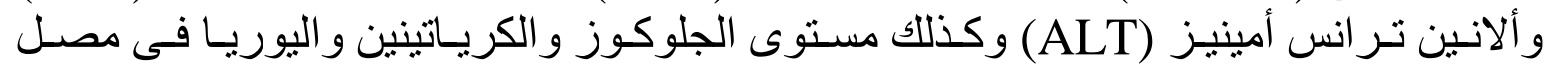

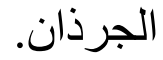
أما بالنسبة للتغير ات الهستولوجية فقد وجد أن السم قد أثثر على تركيب الكبد تأثنير ا بالغا حيث

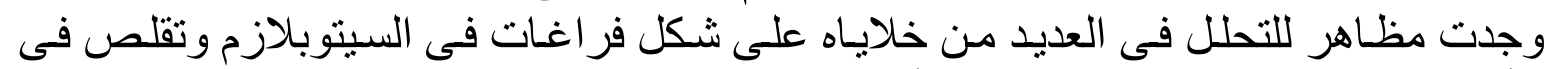

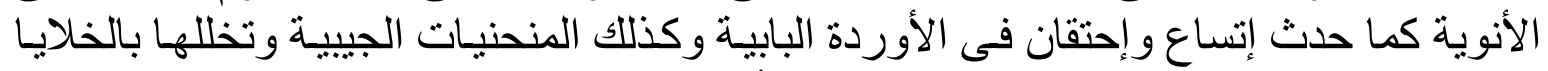

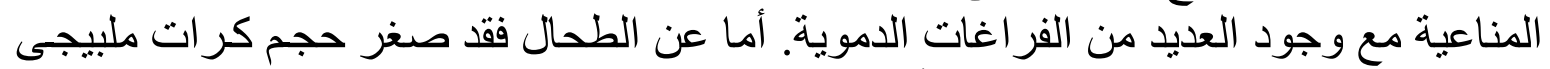

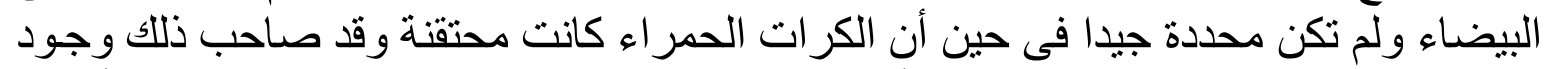

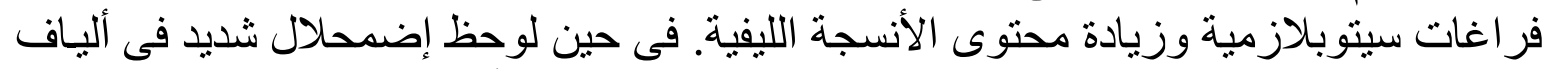

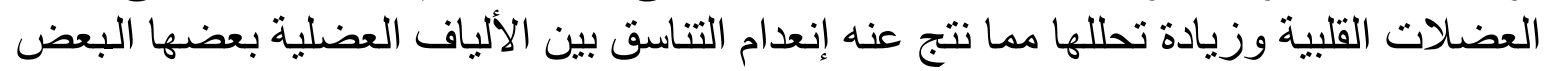

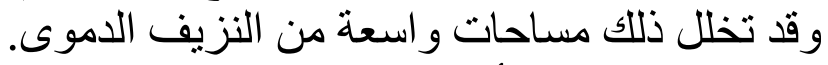

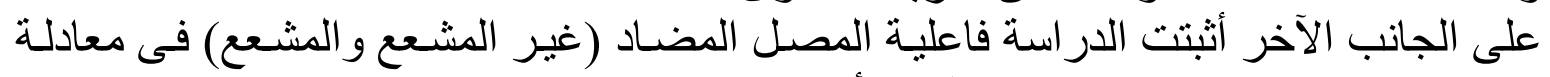

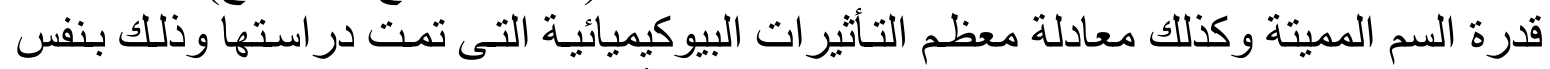

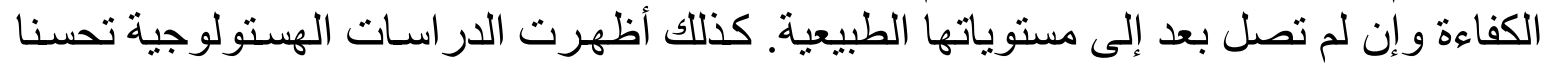

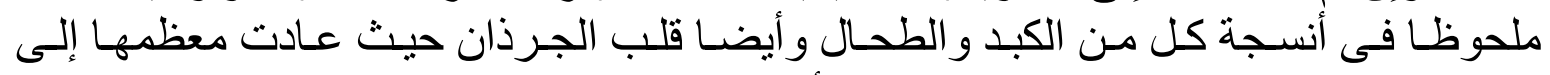
مظهر ها الطبيعى تقريبا بينما لا زالت بل بعض أجز اء منها التعانى من الإصـابة. 


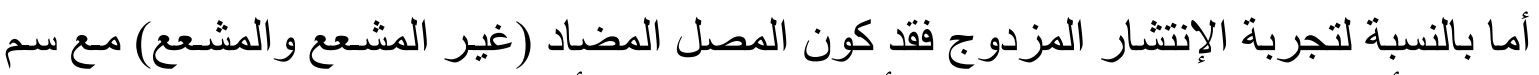

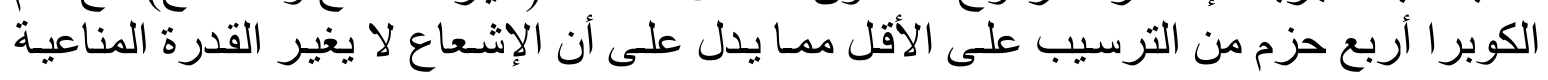

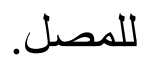

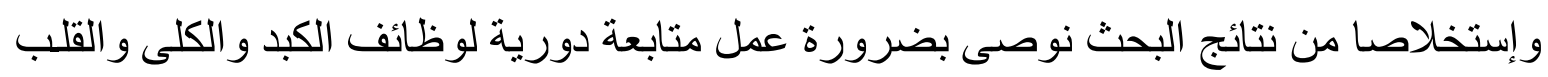

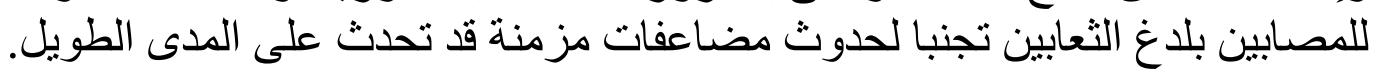

